GA-A20941

\title{
TRANSIENT THERMAL ANALYSIS OF CRYOCONDENSATION PUMP FOR JET
}

\author{
by \\ C.B. BAXI and W. OBERT ${ }^{*}$
}

This is a preprint of a paper presented at the International Cryogenic Engineiering Conference, July 12-16, 1993. Albuquerque, New Mexico, and to be printed in the Proceedings.

\author{
Work supported by \\ U.S. Department of Energy
}

Contract No. DE-AC03-89ER51114

* JET Joint Undertaking, Abingdon, Oxon, OX14 3EA, England.

\section{GENERAL ATOMICS PROJECT 3467 \\ AUGUST 1993}

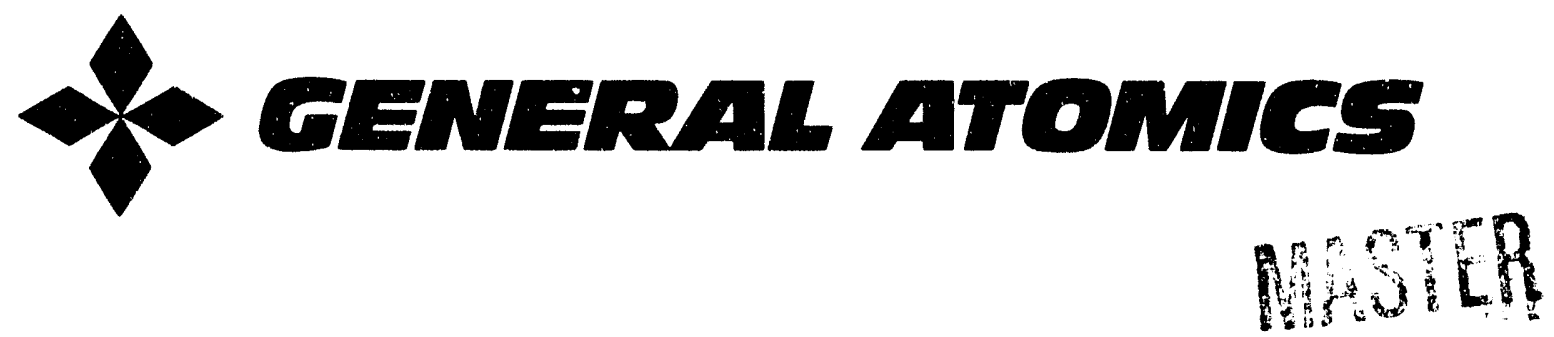




\section{DISCLAIMER}

This report was prepared as an account of work sponsored by an sgency of the United States Government. Neither the United States Government nor any agency thereof, nor any of their employees, mabes any warianty, express or implied, or assumes any legal liability or responaibility for the accuracy, completeness, or usefulneas of any information, apparatus, product, or proces disclosed, or represents that its use would not infringe privately owned rights. Reference herein to any pecific commercial product, proceas, or service by trade name, trademark, manufacturer, or otherwise, does not necessarily constitute or imply its endorsement, recommendation, or favoring by the United States Government or any agency thereof. The views and opinions of authors expressed herein do not neceasarily state or reflect thowe of the United States Government or any agency thereof. 


\title{
TRANSIENT THERMAL ANALYSIS OF CRYOCONDENSATION PUMP FOR JET
}

\author{
C.B. Baxi* and W. Obert** \\ -General Atomics, San Diego, California, 92138-5608 \\ **JET Joint Undertaking, Abingdon, Oxon, OX14 3EA, U.K.
}

\section{ABSTRACT}

A cryopump with pumping speed of $50,000 \mathrm{l} / \mathrm{sec}$ is planned to be installed in the Joint European Torus (JET) as part of the pumped divertor. The purpose of this pump is to control the plasma impurities. The pump consists of a helium panel cooled by supercritical helium and a nitrogen shield cooled by liquid nitrogen. This paper presents the following transient thermal flow analysis for this cryopump:

1. Consequences of loss of torus vacuum on helium panel.

2. Cool down of the nitrogen shield form $300 \mathrm{~K}$ to $80 \mathrm{~K}$.

\section{INTRODUCTION}

It is proposed to install a pumped divertor inside the JET torus to control the plasma impurities. The pumping will be accomplished by a cryocondensation cryopump. Figure 1 shows the design of the proposed pump. The cryopump consists of chevron type liquid nitrogen cooled radiation shield and helium panel cooled by supercritical helium.

The purpose of the nitrogen shield is to reduce the radiation and particle load on the helium panel. The nitrogen shield is made in two parts. The outer shield consists of copper chevrons and the inner shield is a stainless steel plate. Each shield is cooled by liquid nitrogen at a pressure of $4 \mathrm{bar}$ and an inlet temperature of $77 \mathrm{~K}$ flowing through two $19 \mathrm{~mm}$ ID stainless steel tubes.

The helium panel is made from slightly corrugated $20 \mathrm{~mm}$ diameter $0.3 \mathrm{~mm}$ thick stainless steel tubes. Six tubes are used in series to increase the panel area. The area of the helium panel is about $7.5 \mathrm{~m}^{2}$. The helium panel is cooled by supercritica' helium at a pressure of $3 \mathrm{bar}$ and an inlet temperature of $4.2 \mathrm{~K}$.

The details of the design of this pump are given in Obert. ${ }^{1}$

This paper discusses two iransient thermal analyses performed to improve the design and safety of this cryocondensation pump. 


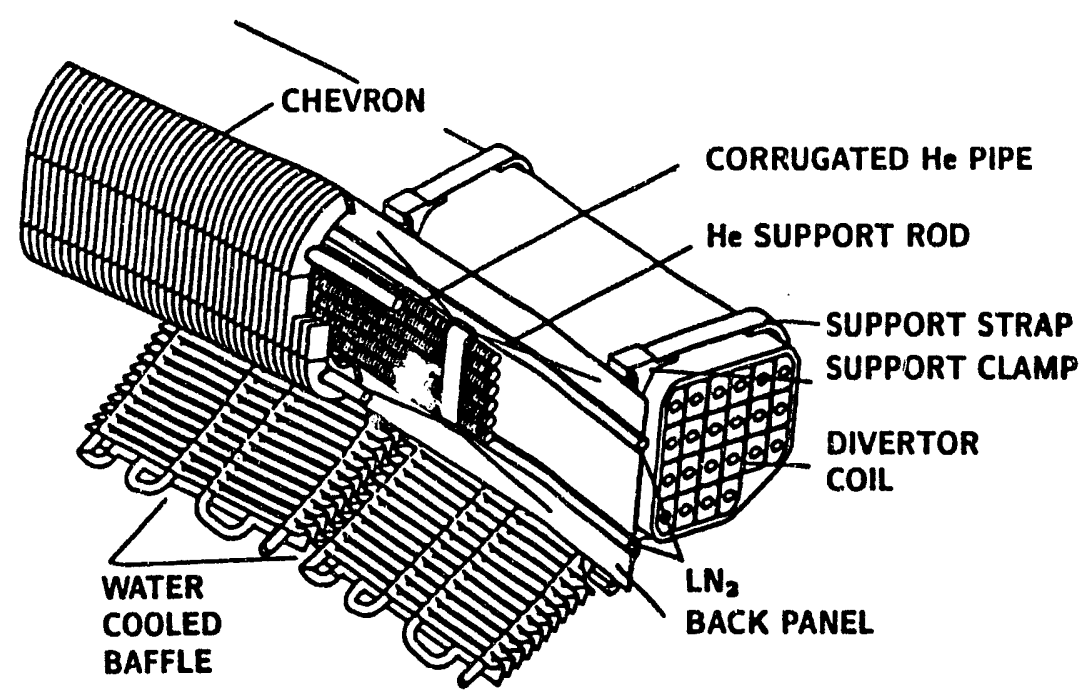

Figure 1. A view of JET pumped divertor cryocondensation pump.

\section{ANALYSIS}

\section{Quench of the Cryopump Helium Panel}

The steady state heat load on the helium panel at this pressure is about $50 \mathrm{~W}$ due to radiation from the $\mathrm{N}_{2}$ shield. Degradation of vacuum in the torus increases the heat load on the helium panel by a factor of up to 60 . The increased heat load on the panel will increase the pressure inside the helium panel and burst the panel tubes. Such an event is prevented by providing a rupture disc activated at 10 bar pressure in the helium line outside the torus. However, due to the long length of the helium panel tube, a rapid pressure increase could cause the tubes to break, before the rupture disc. Hence, an analysis was performed to calculate the expected rise of pressure inside the helium panel.

It is assumed that in the event of an accident the medium in the torus is air. The inlet flow to the helium panel is stopped as soon as loss of vacuum is detected. The heat transfer regime, and thus the heat load on the helium panel, depends on the pressure in the torus. The heat transfer mechanism depends on the mean free path of the medium and the dimensions of the pump.

a. $\mathrm{p}<10^{-6} \mathrm{~Pa}$, the heat load is by radiation heat transfer only.

b. $10^{-6}<\mathrm{p}<0.1 \mathrm{~Pa}$, the heat transfer is by molecular conduction through the gas contained in the torus.

c. $0.1 \mathrm{~Pa}<\mathrm{p}$, heat transfer is by natural convection.

Table 1 summarizes the relation between the torus pressure and heat flux on the helium panel.

Based on the configuration of the cryosystem, it can be assumed that the flow from the helium panel is connected to a sink at a pressure of 3 bar by a co-axial corrugated channel with OD of $3.9 \mathrm{~cm}$ and ID of $1.4 \mathrm{~cm}$. The Moody friction factor for the corrugated channel was taken to be 0.08 based on manufacturers data. The length of the channel is $60 \mathrm{~m}$.

The thermal response of the helium panel can be calculated by solution of continuity, momentum and energy equations.

Pressure and thermal response of the helium panel can now be calculated. A FORTRAN computer program QUENCH.FOR was written for a desktop computer 
Table 1. Effect of pressure on heat transfer

\begin{tabular}{|c|c|c|c|c|}
\hline & \multirow[b]{2}{*}{$\begin{array}{l}\text { Pressure in } \\
\text { Torus (Pa) }\end{array}$} & \multirow[b]{2}{*}{$\begin{array}{l}\text { Heat Transfer } \\
\left(\mathrm{W} / \mathrm{m}^{2}\right)\end{array}$} & \multicolumn{2}{|c|}{ Results } \\
\hline & & & With Flo & No Out Flow \\
\hline 1 & 0.01 & $\begin{array}{l}\text { Molecular conduction } \\
q^{\prime \prime}=2.26 p(80-T)\end{array}$ & $\begin{array}{l}P_{\max }=3 \text { bar pius } \\
\sim 1 \mathrm{~Pa}\end{array}$ & $\begin{array}{l}P=10 \text { bar, } T=5.47 \\
\text { at } 64 \mathrm{~s}\end{array}$ \\
\hline 2 & 0.1 & $\begin{array}{l}\text { Gas conduction } \\
q^{\prime \prime}=0.5(80-T)\end{array}$ & $\begin{array}{l}P_{\max }=3.00086 \text { bar } \\
\text { at } 38 \text { s }\end{array}$ & $\begin{array}{l}P=10 \text { bar, } T=5.47 \\
\text { at } 64 \mathrm{~s}\end{array}$ \\
\hline 3 & $10^{3}$ & $\begin{array}{l}\text { Convection } \\
q^{\prime \prime}=0.527(80-T)^{1.25}\end{array}$ & $\begin{array}{l}P_{\max }=3.002 \mathrm{bar} \\
\text { at } 10 \mathrm{~s} \\
T \simeq 80 \mathrm{~K} \text { at } 605 \mathrm{~s}\end{array}$ & $\begin{array}{l}P=10 \mathrm{bar}, T=5.47 \\
\text { at } 20 \mathrm{~s}\end{array}$ \\
\hline 4 & $10^{6}$ & $\begin{array}{l}\text { Convection } \\
q^{\prime \prime}=0.527(80-T)^{1.25}\end{array}$ & $\begin{array}{l}P_{\max }=3.108 \mathrm{bar} \\
\text { at } 0.98 \mathrm{~s} \\
T \simeq 80 \mathrm{~K} \text { at } 63 \mathrm{~s}\end{array}$ & $\begin{array}{l}P=10 \text { bar, } T=5.47 \\
\text { at } 2 \text { s }\end{array}$ \\
\hline
\end{tabular}

$q^{\prime \prime}=$ Heat flux on the helium panel

$T=$ Temperature of the helium panel

to solve the above set of equations by an implicit numerical procedure. Properties of helium were used from Hands. ${ }^{2}$

An analysis was performed for four pressure levels covering all regimes. Two conditions were considered. With the outflow (flow out of the helium panel to a sink at 3 bar) occurring or with no outflow. The results are summarized in Table 1.

The results show that if the outflow occurs, the pressure increase in the helium panel is quite small. The rupture disc will not break. The flow resistance of the outflow channel is so small tha? it acts as a safety valve. If the outflow did not occur, 10 bar pressure is reached when the temperature is $5.47 \mathrm{~K}$. The time required to reach this pressure is $2 \mathrm{~s}$ if the torus pressure is $10^{5} \mathrm{~Pa}$ and is $1400 \mathrm{~s}$, if the torus pressure is $0.01 \mathrm{~Pa}$. Response of the helium panel when the torus pressure is $0.01 \mathrm{Fa}$ is shown in Fig. 2. As long as the outflow occurs, the pressure in the helium panel does not increase significantly during the quench. Thesults obtained in this analysis agree within $20 \%$ with the approximate relation (modified to sccount for large friction factor in corrugated channel) presented in Miller et al. ${ }^{3}$

\section{Cool Down of Nitrogen Shield}

The helium panel is surrounded by a $\mathrm{N}_{2}$ shield in the proposed JET cryocondensation pump as shown in Fig. 1. The outer $\mathrm{N}_{2}$ shield consists of copper chevrons and the inner $\mathrm{N}_{2}$ shield consists of a stainless steel plate. Both $\mathrm{N}_{2}$ shields are cooled by liquid $N_{2}$ at a pressure of 4 bar and $77 \mathrm{~K}$. The outer shield is directly mounted on the inner shield in the reference design.

The objective of this analysis was to investigate the consequence of cooling down the nitrogen shields from initial temperature of $300 \mathrm{~K}$ to $80 \mathrm{~K}$ by use of liquid $\mathrm{N}_{2}$. A matter of concern was the temperature differences and resulting thermal stresses between different parts of the $\mathrm{N}_{2}$ shield during such a cool down.

In order to analyze this problem, a computer code was developed which modeled the geometry of the $\mathrm{N}_{2}$ shields and the phase transition of the $\mathrm{N}_{2}$ during flow through the shield.

The governing equations and details of this model are given in Baxi. ${ }^{4}$ An implicit numerical procedure was used which enabled time steps of about 18 . 


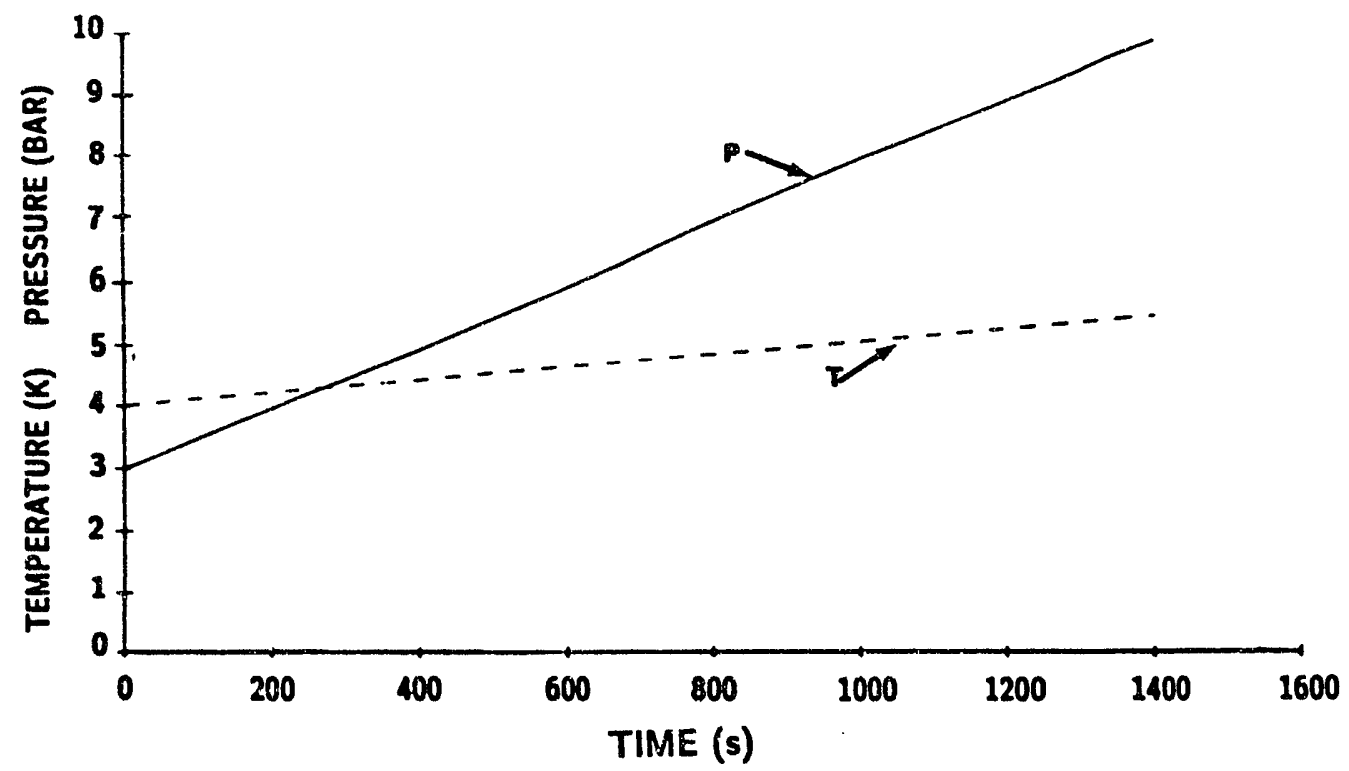

Figure 2. Response of helium panel with ambient pressure $=0.01 \mathrm{~Pa}$ and no out slow.

The cooling tubes on the shield can be connected in a number of different ways (Fig. 3). During the cool down of the shield from $300 \mathrm{~K}$ to $80 \mathrm{~K}$, the temperature difference of between the shields varies as a function of time, calculated by the model, as shown in Fig. 4. Results for all flow arrangements are summarized in Table 2, indicating that arrangement II results in a minimum temperature difference.

Another effect analyzed with the computer program was the effect of adding a copper layer of about $1 \mathrm{~mm}$ thickness to the stainless steel shield. Such a layer will reduce the steady state temperature of the stainless steel shield and also reduce the temperature difference between outer and inner shields from $82 \mathrm{~K}$ to $65 \mathrm{~K}$ during the cool down (Table 2).
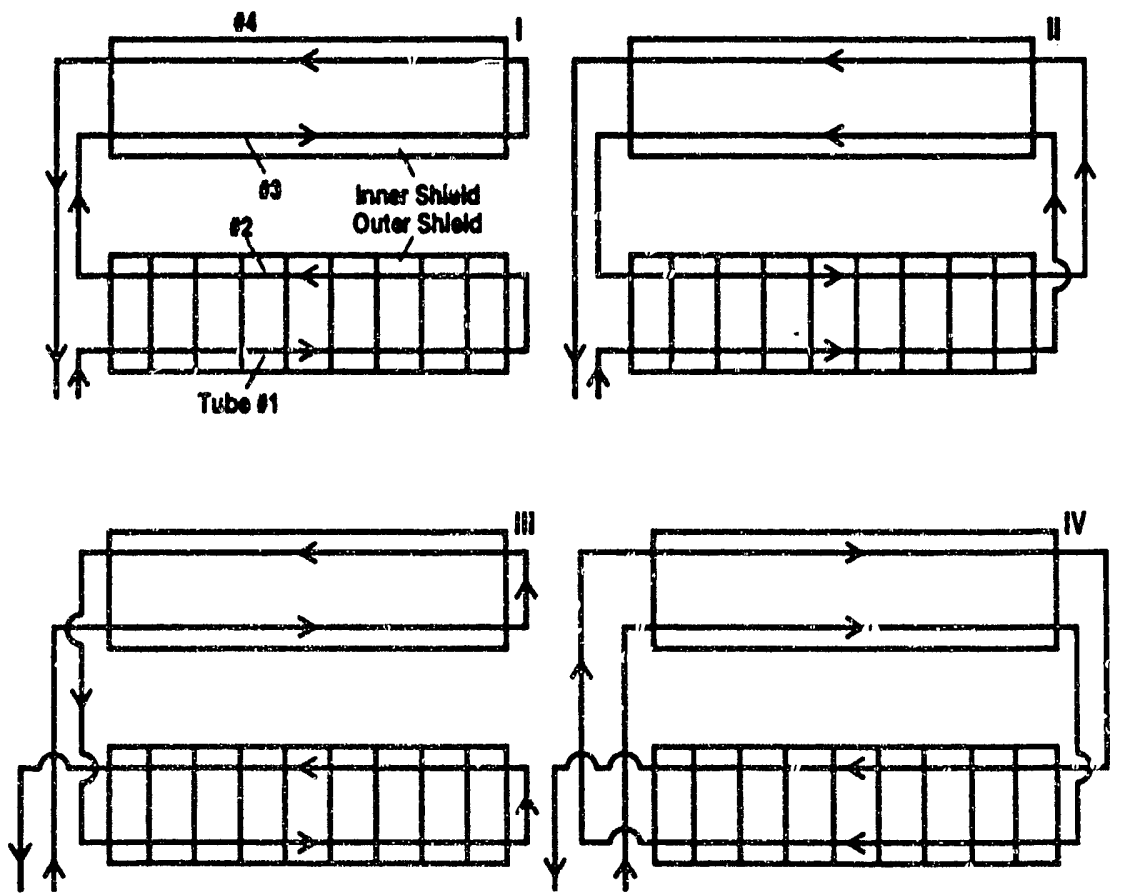

Figure 3. Arrangements for connecting cooling tubes of the nitrogen shields. 


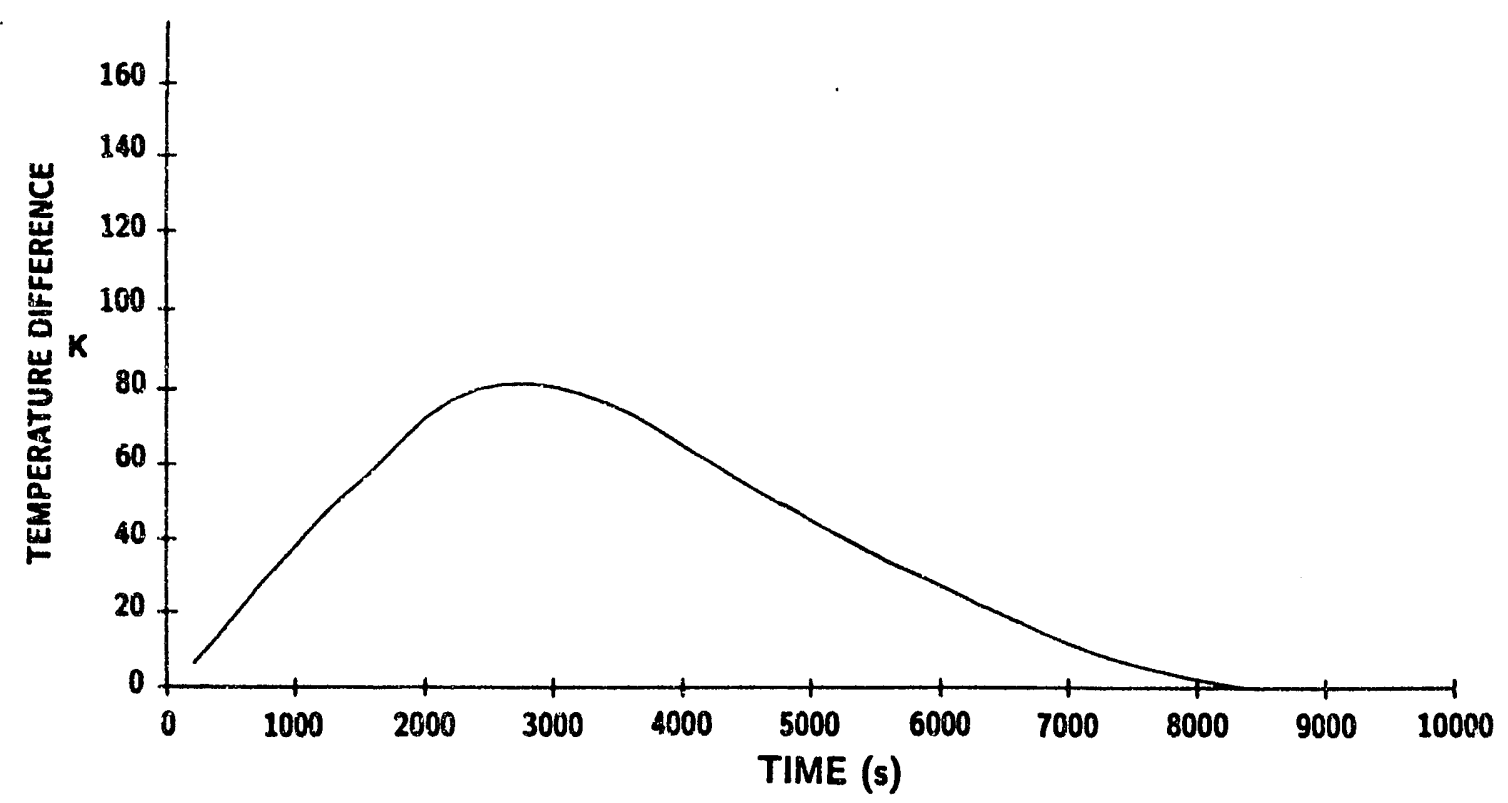

Figure 4. Difference between outer shield and inner shield (Flow $=7.5 \mathrm{~g} / \mathrm{s}$, Arrangement II, Heat Loßd $\simeq 1 \mathrm{~kW}$ ).

Table 2. Effect of flow arrangement on temperature difference between chevrons and stainless steel shield $7.5 \mathrm{~g} / \mathrm{s}$ flow, $1 \mathrm{~kW}$ heat load

\begin{tabular}{lcc}
\hline Arrangement & $\begin{array}{l}\text { Without } \\
\text { Copper Layer }\end{array}$ & $\begin{array}{l}\text { With 1 mm Copper } \\
\text { Layer on Inner Shield }\end{array}$ \\
\hline I & 105 & 98 \\
II & 82 & 65 \\
III & 200 & 158 \\
IV & 87 & 73 \\
\hline
\end{tabular}

Parametric studies showed that the temperature difference between the shield increased by about $5 \mathrm{~K}$ if the flow rate of liquid $\mathrm{N}_{2}$ was doubled from $7.5 \mathrm{~g} / \mathrm{s}$ to $15 \mathrm{~g} / \mathrm{s}$. If heat load was increased from base condition of $1 \mathrm{~kW}$, the temperature difference decreased to $50 \mathrm{~K}$ (Tables 2 and 3).

Table 3. Effect of Flow Rate on Temperature Difference between inner and outer shields (arrangement II, with $1 \mathrm{~mm}$ copper layer on inner shield and heat load of $1 \mathrm{~kW}$ )

\begin{tabular}{cc}
\hline$N_{2}$ Flow Rate $(\mathrm{g} / \mathrm{s})$ & Temperature Difference $(\mathbf{k})$ \\
\hline 3.75 & 59 \\
7.50 & 65 \\
15.00 & 70 \\
\hline
\end{tabular}

This analysis shows that the temperature difference between the inner and outer $\mathrm{N}_{2}$ can be reduced but can not be eliminated by optimizing the design. Hence it was decided to modify the design to permit small relative motion between the inner and 
outer $\mathrm{N}_{2}$ shields to reduce the stresses caused during cooldown transients. An alternative would have been to have a controlled cooldown, where $\mathrm{N}_{2}$ gas at a controlled temperature is used to cool down the $\mathrm{N}_{2}$ shields.

As a result of this analysis following three design modifications were suggested for the nitrogen shield design:

1. Concept of controlled cooling of the shield with a $50 \mathrm{~K}$ temperature ciifference between outlet and inlet coolant during cooldown, should be sbandoned.

2. A copper layer of $1 \mathrm{~mm}$ equivalent thickness should be used on the stainless steel shield.

3. A sliding joint should be provided between inner and outer shield to allow relative motion of about $5 \mathrm{~mm}$ expected during cooldown.

\section{CONCLUSIONS}

1. Loss of vacuum in the torus does not result in rupture of the helium panel tubes.

2. There is no need to have a controlled cooling of the nitrogen shield. Liquid nitrogen can be used to cool the nitrogen shield from $300 \mathrm{~K}$ to $80 \mathrm{~K}$.

3. Addition of copper layer on the $\mathrm{N}_{2}$ shield will reduce the temperature differences.

4. A sliding joint between outer and inner $\mathrm{N}_{2}$ shield is recommended to reduce stresses during cool down.

5. The flow arrangement shown in Fig. 3-II, will result in minimum temperature differences during the cooldown.

\section{ACKNOWLEDGEMENT}

This work was performed during C.B. Baxi's visit to JET in 1991 and was sponsored by the U.S. Department of Energy under Contract No. DE-AC03-89ER51114. The authors wish to thank G. Perinic for his help during the course of this work.

\section{REFERENCES}

1 W. Obert, et al., "JET Pumped Divertor Cryopump," Presented at the SOFT 16, London, (1990).

2. B.A. Hanc', "HEPROP," 1289/79, Engineering Laboratory, Oxford University.

3. J.R. Miller, et al., "Pressure Rise During the Quench of a Superconducting Magnet Using Internally Cooled Conductors," CEC Conference Proceedings, (1981) pg. 321-327.

4. C.B. Baxi, "Trip Report: Visit to JET," General Atomics Report GA-C20826, January 1992. 
1
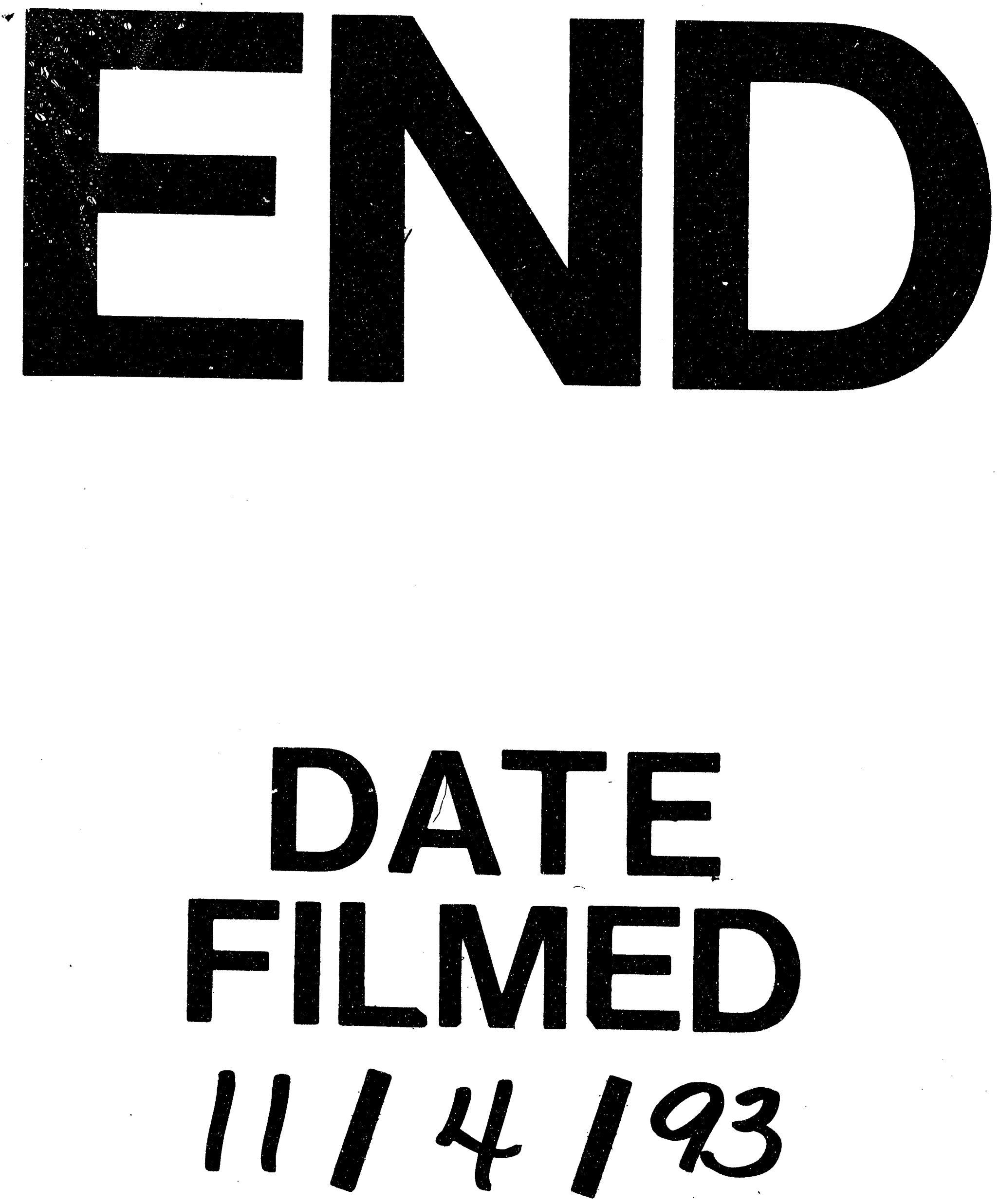
